\begin{tabular}{|c|c|c|}
\hline & $\begin{array}{c}\text { GEOAMBIENTE ON-LINE } \\
\text { Revista Eletrônica do Curso de Geografia - UFG/REJ } \\
\text { Graduação e Pós-Graduação em Geografia } \\
\text { htpp://www.revistas.ufg.br/geoambiente } \\
\text { Jataí-Go | n } 31 \text { | Maio-Agosto/2018 }\end{array}$ & $\begin{array}{c}\text { ISSN 1679-9860 } \\
\text { IE }\end{array}$ \\
\hline
\end{tabular}

\title{
A TEMÁTICA AMBIENTAL EM ÁREAS URBANAS: O RIO POTI COMO OBJETO DE ESTUDO EM TERESINA/PIAUÍ
}

\author{
"Hikaro Kayo de Brito Nunes ${ }^{1}$, Cláudia Maria Sabóia de Aquino \\ (1 - Universidade Federal do Piaiu, Mestrando em Geografia, hikarokayo2@hotmail.com, 2 - \\ Universidade Federal do Piaui, Docente do Programa de Pós-Graduação em Geografia, \\ cmsaboia@gmail.com)
}

Resumo: Este trabalho visa discutir a problemática socioambiental urbana de Teresina/Piauí com base em trabalhos realizados tendo o rio Poti como objeto de estudo. Dessa forma, o trabalho se caracteriza como sendo um estado da arte, fazendo uso de uma revisão temática e aplicada de reflexões sobre os referidos temas objetos do estudo.Findada a análise dos materiais (publicados entre 2008 e 2016), confirma-se o papel intrínseco da relação sociedade-natureza no campo geográfico, concordando com a ideia de que não há Geografia sem sociedade, apoiando-se nela as análises geográficas fixadas num ambiente natural atuante. Isto posto, a multiplicidade de abordagens referentes à problemática socioambiental urbana em especial sua relação com o Poti evidencia a complexidade dos estudos, tanto em temas abordados quanto metodologias aplicadas. Por fim, apresenta-se a espacialização destes estudos, tendo sido os mesmos categorizados em microescala, mesoescala e macroescala. Quantitativamente, apesar de uma considerável quantidade de trabalhos (17) notou-se uma repetição de temas abordados como enchentes, inundações e vulnerabilidades, haja vista o comportamento do rio quando da época de intensas precipitações, tendo íntima relação com a ocupação das suas margens e qualidade ambiental.

Palavras-chave: meio ambiente urbano; rio Poti; estado da arte.

\section{THE ENVIRONMENTAL THEMATICS IN THE URBAN AREAS: THE POTI RIVER AS A STUDY OBJECT IN TERESINA / PIAUÍ}

Abstract: This article intends to discuss the social-environmental problematic of Teresina / Piauí based on the work done with the Poti River as an object of study. In this way, the work is characterized as a state of the art, making use of a thematic review and applied reflections

\footnotetext{
Artigo recebido para publicação em 28 de Junho de 2017
}

Artigo aprovado para publicação em 16 de Maio de 2018 


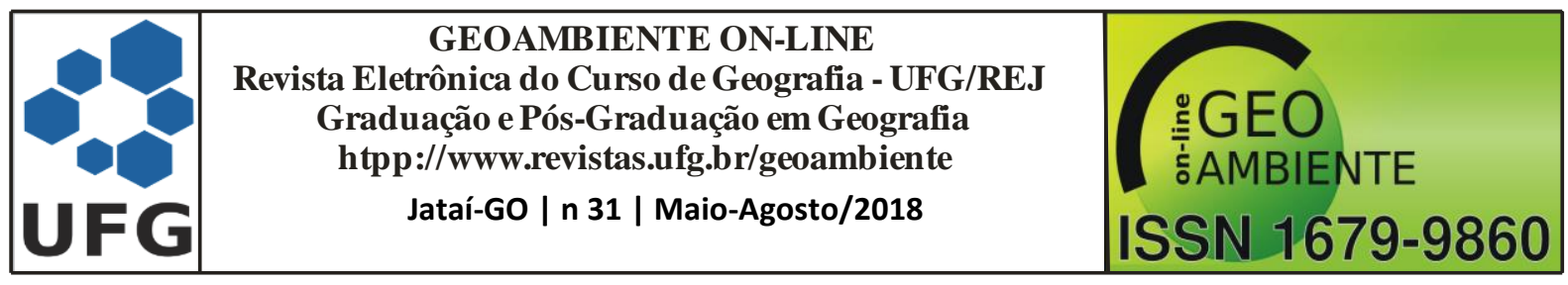

on the issues. After the analysis (between 2008 and 2016), of the materials, the intrinsic role of the society-nature relationship in the geographic field is confirmed, agreeing with the idea that there is no Geography without society, being based on it the geographic analyzes set in a natural environment.This fact, the multiplicity of approaches referring to urban socioenvironmental problems, especially its relation with Poti, shows the complexity of the studies, both in the themactic approached and applied methodologies. Finally, we present the spatialization of these studies, being the same categorized in microscale, mesoscale and macroscale. Quantitatively, despite a considerable amount of production (17), there was a repetition of themes such as floods, inundations and vulnerabilities, due to the river's behavior during the intense rainy season, closely related to the occupation of its margins and environmental quality.

Keywords: urban environment; Poti River; state of art.

\section{LA TEMÁTICA AMBIENTAL EN ÁREAS URBANAS: EL RIO POTI COMO OBJETO DE ESTUDIO EN TERESINA / PIAUÍ}

Resumén: Este trabajo busca discutir la problemática socioambiental urbana de Teresina / Piauí con base entrabajos realizados teniendo el río Poti como objeto de estudio. De esta forma, eltrabajo se caracteriza como un estado del arte, haciendo uso de una revisión tematica y aplicada de reflexiones sobre las cuestiones. Findada la análisis de los materiales (entre 2008 y 2016), se confirma el papel intrínseco de la relación entre la sociedad y naturaleza en el ámbito geográfico, acordando con la idea de que no hay Geografía sin sociedad, apoyándose en ella las análisis geográficas fijadas en un ambiente natural activo. Esto puesto, la multiplicidad de enfoques relativos a la problemática socioambiental urbana con especial su relación con el Poti evidencia la complejidad de los estudios, tanto en temas abordados como metodologías aplicadas. Por último, se muestra la distribución espacial de estos estudios, teniendo sido los mismos categorizados en microescala, mesoescala y macroescala. Cuantitativamente, a pesar de una considerable cantidad de producciónes (17) se ha notado una repetición de temas abordados como enchentes, inundación y vulnerabilidad, teniendo en cuenta lo comportamiento del rio cuando el tiempo de intensas precipitaciones, teniendo íntima relación con la ocupación de sus márgenes y calidad ambiental.

Palabras clave: medio ambiente urbano; Río Poti; estado del arte. 


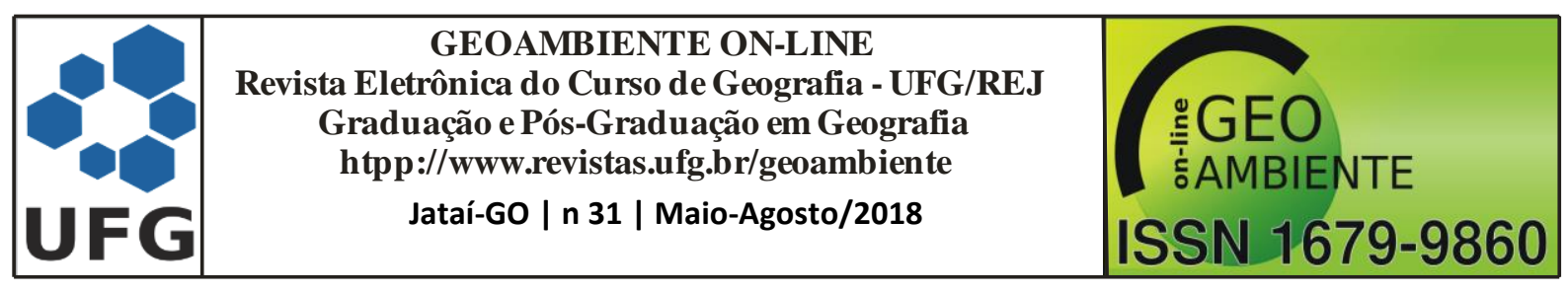

\section{Introdução}

Adiscussão ambiental tem tido um aumento significativo no número de trabalhos em áreas urbanas, mesmo que em temáticas e contextos diversos. Associada à essa demanda de discussões e relacionando com a possibilidade de atuação da Geografia,se parte do pressuposto que há na sociedade atual um vasto campo para a ciência geográfica, e, com essa ideia, sabe-se ainda que há muito o que ser feito e discutido.

O fenômeno da urbanização ocorrido no Brasil causou um aumento considerável do número de cidades, de forma acelerada e desorganizada, não havendo assim, uma resposta positiva na relação infra-estrutura urbana e demanda populacional. Sobre isso, Rossato (1996) relata que o crescimento acelerado dos grandes centros urbanos e a diminuição progressiva da população relativa das pequenas cidades é uma das características mais evidente desse processo no país.

Dessa maneira, quando postos de forma relacionada meio ambiente e cidades, tem-se que os problemas ambientais resultam do não atendimento dos limites (capacidade do meio) da utilização do meio físico. Assim, ao modificar a natureza com a construção de casas, estradas e demais formas de apropriação do espaço, a população das cidades sofre com a queda da qualidade ambiental, o que interfere também na qualidade de vida, na saúde pública, na exposição da sociedade a vulnerabilidades, dentre outras respostas socioambientais.

Sobre as vulnerabilidades, este é um conceito alvo de estudo de variados ramos do conhecimento e caracterizado por Deschamps (2004) como uma possibilidade útil e potente para investigar múltiplos aspectos da sociedade. Pelling (2003) corrobora a ideia anteriormente citada ao afirmar que a vulnerabilidade se manifesta quando da existência de riscos e à incapacidade de evitar ou absorver danos em potencial, sendo ainda dividida em três categorias: física, social e humana. Concorda-se aqui ao expor que o espaço geográfico é possuidor de articulações envolvendo características naturais (haja vista se assentar sobre um substrato físico-natural) e sociais (culturais, econômicas, histórica e etc.) nas quais se intensificam as limitações do ambiente.

Diante da relação Geografia, Meio Ambiente, Sociedade e Cidade, o presente manuscrito tem como objetivo discutir a problemática socioambiental urbana de Teresina/Piauí com base em trabalhos realizados tendo o rio Poti como objeto de estudo. Justifica-se portanto, a necessidade de se realizar reflexões no que se refere às questões da 


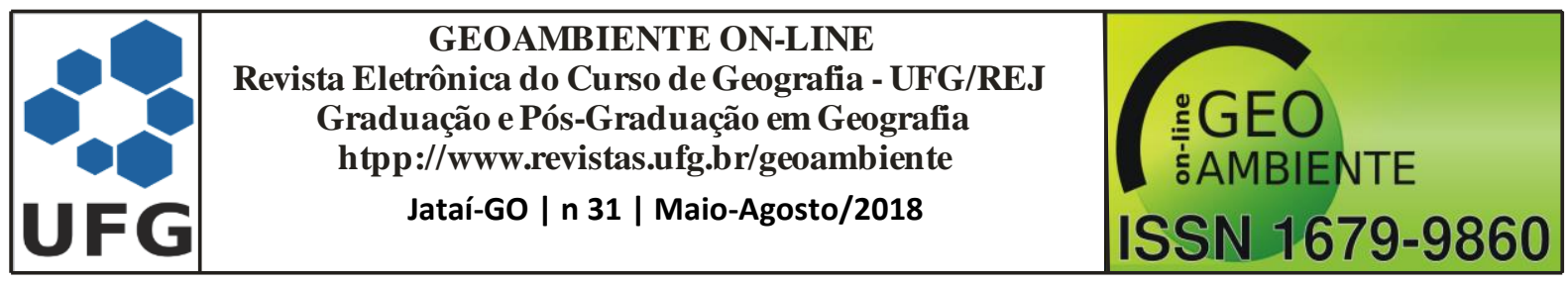

problemática socioambiental urbana, contribuindo assim,para a sua amplitude de atuação e disseminação do conhecimento.

Metodologicamente, esta pesquisa se apresenta como um estado da arte, portanto, será exposta uma análise sobre o que já foi produzido relacionado ao tema. A compreensão deste estado de conhecimento temático faz parte do processo de evolução da ciência, haja vista o ordenamento periódico de conhecimentos já obtidos, permitindo, dentre outras coisas, a integração e comparação destes escritos em um único compilado de informações.

\section{Cidades e problemática socioambiental}

O conceito de cidade está vinculado a várias concepções teóricas, estando, assim, inserido em um amplo debate conceitual.A discussão presente em torno do mesmo se baseia em uma série de características, como a densidade demográfica, a extensão territorial e até mesmo o papel do mercado, entre outros. No Quadro 1, tem-se um perfil comparativo, destacando as contribuições de alguns autores a respeito.

Notadamente, percebe-se que, para muitos autores, a cidade é um reflexo das relações sociais instaladas em uma superfície natural. Sustentando a ideia de Verona, Galina e Troppmair (2003), os impactos ambientais originados pela pressão da urbanização são oriundos de necessidades socioeconômicas, impactando com maior ou menor intensidade o referido ambiente citadino.

Ademais, é necessário compreender que ao se discutir o conceito de cidade é fundamental investigar outras questões que se fazem necessárias. Ratifica-se aqui as três questões expostas por Vasconcelos (2015): a) existência de questões políticas; b) contexto histórico; e c) em que espaço geográfico (e temporal) o conceito foi criado. $\mathrm{O}$ autor vai mais além, e, temporalmente, divide os conceitos de cidade em seis períodos, a saber: a) período pré-acadêmico (1810-1869); b) período da institucionalização das ciências sociais (18701913); c) período entre as guerras mundiais (1914-1944); d) período do pós-guerra (19451972); e) período do início da crise atual (1973-1994) e f) o período atual (1995-).

Comparando-se o exposto no quadro 1 e as considerações de Vasconcelos (2015), afirma-se que o conceitos anteriormente listados estão enquadrados em três períodos (o da institucionalização das ciências sociais, o do início da crise atual e o do período atual), e, nesse sentido, percebe-se o quanto o conceito é dinâmico. 


\begin{tabular}{|c|c|c|}
\hline & $\begin{array}{c}\text { GEOAMBIENTE ON-LINE } \\
\text { Revista Eletrônica do Curso de Geografia - UFG/REJ } \\
\text { Graduação e Pós-Graduação em Geografia } \\
\text { htpp://www.revistas.ufg.br/geoambiente } \\
\text { Jataí-Go | n } 31 \text { | Maio-Agosto/2018 }\end{array}$ & $\begin{array}{c}\text { ISEN } \\
\text { G }\end{array}$ \\
\hline
\end{tabular}

Quadro 1 - Contribuição de alguns autores frente ao conceito de cidade

\begin{tabular}{|c|c|}
\hline AUTORES & CONTRIBUIÇÃO \\
\hline Ratzel & $\begin{array}{l}\text { "Reunião durável de homens e habitações que cobre uma grande } \\
\text { superfície e se encontra no cruzamento de grandes vias comerciais" } \\
\text { (RATZEL apud CARLOS, 2007, p. 67). }\end{array}$ \\
\hline Sposito (1988) & $\begin{array}{l}\text { Produto cumulativo das transformações sociais ao longo dos tempos, } \\
\text { geradas pelas relações sociais promovidas por essas transformações, } \\
\text { sendo o locus e produtor das relações sociais, ao mesmo tempo. }\end{array}$ \\
\hline $\begin{array}{l}\text { Rodrigues } \\
\text { (1998) }\end{array}$ & $\begin{array}{l}\text { Locus privilegiado da produção e do consumo, é também o lugar } \\
\text { privilegiado de circulação de informações, idéias e ideários. }\end{array}$ \\
\hline Callai (2000) & $\begin{array}{l}\text { Espaço onde se concentra a população e onde acontecem de maneira } \\
\text { mais acentuada as relações humanas com extensão e complexidade } \\
\text { evidentes. }\end{array}$ \\
\hline $\begin{array}{l}\text { Verona; Galina } \\
\text { e Troppmair } \\
\text { (2003) }\end{array}$ & $\begin{array}{l}\text { É a materialidade das interferências humanas mais marcantes de } \\
\text { transformações da natureza e é ela que representa o auge das relações } \\
\text { sociais. }\end{array}$ \\
\hline Côrrea (2005) & $\begin{array}{l}\text { Faz uma interpretação sobre a cidade como espaço urbano, este sendo } \\
\text { simultaneamente, fragmentado e articulado, desigual e mutável, reflexo } \\
\text { da sociedade e expressão espacial de processos sociais. }\end{array}$ \\
\hline Carlos (2007) & $\begin{array}{l}\text { Deve ser discutida na sua articulação com a sociedade global, sendo } \\
\text { ainda, uma realização humana e de construção ininterrupta. }\end{array}$ \\
\hline Souza (2008) & $\begin{array}{l}\text { Espaço onde se concentra possibilidades de satisfação das necessidades } \\
\text { básicas materiais e imateriais, além de ser um local crescentemente } \\
\text { poluído. }\end{array}$ \\
\hline
\end{tabular}

Fonte: Organização dos autores, 2017.

Partindo dessa abordagem, por se tratar de um estudo integrado, torna-se fundamental uma relação dialética entre sociedade e meio ambiente. Conforme Rodrigues (1998), a questão ambiental deve ser compreendida como um produto da intervenção da sociedade sobre a natureza, o que diz respeito não apenas a problemas relacionados à natureza, mas às questões decorrentes da ação social. No que se refere ao meio ambiente urbano, a autora defende que este seja o conjunto das edificações, com suas características construtivas, sua história e memória, seus espaços segregados, a infraestrutura e os equipamentos de consumo coletivos.

Desse modo, as questões ambientais devem ser analisadas a partir da relação naturezasociedade, poisos agentes sociais, políticos e econômicos usam os componentes ambientais de acordo com seus interesses. Em síntese, os problemas ambientais urbanos decorrem a partir do relacionamento entre os assentamentos humanos e seu suporte físico, e há, com base nisso, 




a necessidade de haver uma sustentabilidade ambiental que para Rodriguez e Silva (2001) abrange três categorias: a geoecológica, a econômica e a sociocultural.

Com o aumento do perímetro urbano ou até mesmo de obras de construção civil associadas ao crescimento populacional e a crescente demanda por infraestrutura, a paisagem local sofre um conjunto de interferências. Dentro dessas intervenções, podem ser citadas a retirada da vegetação da área, a compactação do solo e sua consequente impermeabilização, alteração da geomorfologia da área, além de alterações no microclima, haja vista a retirada da vegetação e o aumento da cobertura asfáltica.

Assim sendo, é necessária uma preocupação na relação sociedade-natureza de modo que implique em um estilo de desenvolvimento, que, poderá ser gerenciado pelo Estado deixando intrínseca as temáticas urbanas e ambientais, além de mitigar os inúmeros casos de descaracterização do ambiente natural (muitas vezes irreversíveis)o que provoca a intensificaçãoda problemática socioambiental urbana.

Peixoto (2005) afirma que a concentração da população brasileira nas áreas urbanas, aliada às restrições econômicas que atingem a sociedade e às limitações das administrações públicas em relação ao planejamento e ao controle do uso e ocupação do solo, reforça o caráter informal e aparentemente anárquico da urbanização brasileira.

Nesse sentido, há um agravamento dos processos de segregação espacial, exclusão social e degradação ambiental. Fernandes (2002, p. 244) coloca o foco na discussão no meio ambiente urbano, por ser importante, necessária e urgente devido ao fato de que a maioria da população brasileira vive nas cidades e que "[...] o modelo urbano industrial já provocou mudanças sócio espaciais drásticas no Brasil, bem como consequências ambientais muito graves, cujas implicações podem ser tecnicamente comparadas aos efeitos das grandes catástrofes naturais".

O ambiente urbano, por exemplo, sedia o choque de interesses e de realizações.De um lado o que está posto nos ambientes naturais, e, do outro os mecanismos socioeconômicos, promovendo assim uma relação complexa de atuação e sobreposição de interesses. Possui destaque a construção civil,que se caracteriza como atividade que atinge diretamente a sociedade, considerando o leque de intervenções ligadas a ela, podendo alterar a vida de inúmeros atores sociais, em que essas auxiliam na geração de benefícios e malefícios para as 


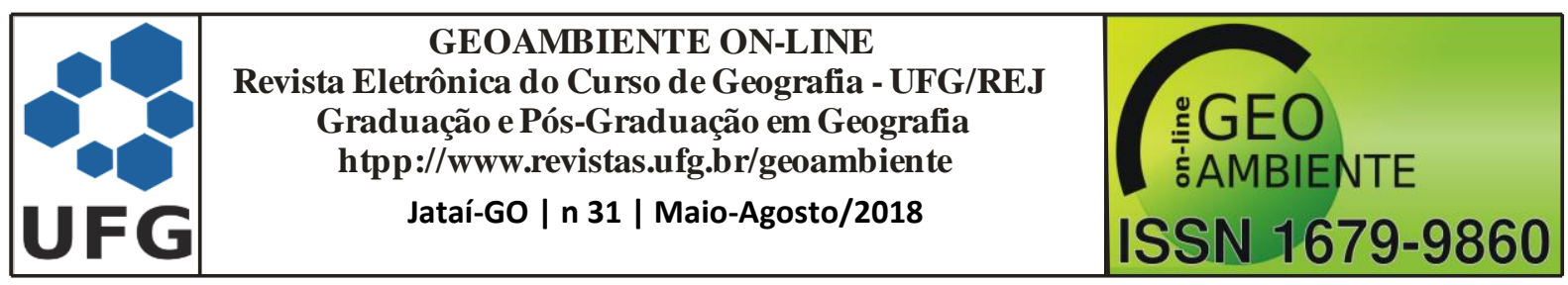

pessoas que estão ligadas a determinada área. A própria ocupação urbana deriva, em alguns casos, da construção civil, sendo esta um dos seus instrumentos.

Para que se possa traçar uma análise sobre os impactos ambientais é necessário que se verifique as alterações decorrentes, segundo Reis (2005) por processos tecnológicos nos sistemas atuantes no meio ambiente (meios físicos, bióticos e antrópicos). Nesta discussão é importante ressaltar o que foi mencionado por Coates (1976) apud Jorge (2011, p. 131), que "no ambiente urbano o homem é o criador da paisagem (landscape), ou da paisagem da cidade (cityscape), pois o mesmo, ao ocupar e criar ambientes artificiais, distorce uma parte ou grande parte das áreas urbanas". Esses impactos (podendo ser positivos e negativos) tomam em alguns casos grandes dimensões, visto a amplitude de seus projetos.

Ao ponto que o homem se caracteriza como um ser modificador da natureza, este acaba incorporando características através do desenvolvimento de suas técnicas de trabalho e de apropriação da natureza, tornando-o um agente geomorfológicocomo citado por Rodrigues (1999) apud Santos Filho (2011), além de interferir nas condições climáticas, pedológicas, geológicas, biogeográficas urbana, deturpando, de um ambiente natural para um ambiente cada vez maisartificial decorrente do processo constante de urbanização, industrialização e etc.

\section{Trabalhos sobre a temática ambiental em áreas urbanas: a relação Teresina e rio Poti}

\section{Localização geográfica e situação de pressão antrópica}

No município de Teresina, principalmente na zona urbana,é onde o rio Poti entra em contato com a maior pressão antrópica (motivada pela urbanização) durante todo o seu curso. Teresina é a capital do estado do Piauí, localizada na mesorregião do Centro-Norte Piauiense e na microrregião homônima, estando situada no estágio finaldo médio curso do rio Parnaíba e caracterizada como a única capital do Nordeste fora da zona costeira.

Conforme dados de SEMPLAN (2016),a área do município de Teresina é de 1.392 $\mathrm{km}^{2}(0,55 \%$ do território piauiense) e limítrofe a 11 municípios, sendo: ao Norte (União e José de Freitas); a Leste (Altos, Lagoa do Piauí e Pau D’Arco do Piauí); ao Sul (Palmeirais, Monsenhor Gil; Nazária; Demerval Lobão e Curralinhos); e a Oeste (Timon - Maranhão). Teresina compõe também a Região Integrada de Desenvolvimento (RIDE) da Grande 




Teresina, composta pelos municípios anteriormente citados (exceto Palmeirais) além de Coivaras (a Leste), Beneditinos (a Leste), Lagoa Alegre (ao Norte) e Miguel Leão (ao Sul).

A paisagem urbana de Teresina (figura 1) foi remodelada com o passar do tempo, seja pelo poder público, seja por interesses particulares e ocupações espontâneas (com invasão de áreas públicas e particulares), o que favoreceu uma espacialização das classes sociais e caracterizando ainda o rio Poti como um importante elemento nessa dinâmica urbana, mesmo apropriado de forma irregular, principalmente em suas margens. Há ainda o fato da existência de terrenos particulares próximos às margens do rio Poti permitindo-se inferir a especulação imobiliária, como aponta Nunes (2017).

Figura 1 - Localização geográfica da cidade de Teresina (Piauí)



Organização: Os autores, 2017.

Perante o exposto, os espaços marginais do rio Poti acabaram sendo ambientes contrastantes. Nunes (2017) relata que na área rural há uma predisposição para as atividades de lavoura e pecuária, com a presença de sítios e fazendas; nas regiões Sul, Sudeste e porção 


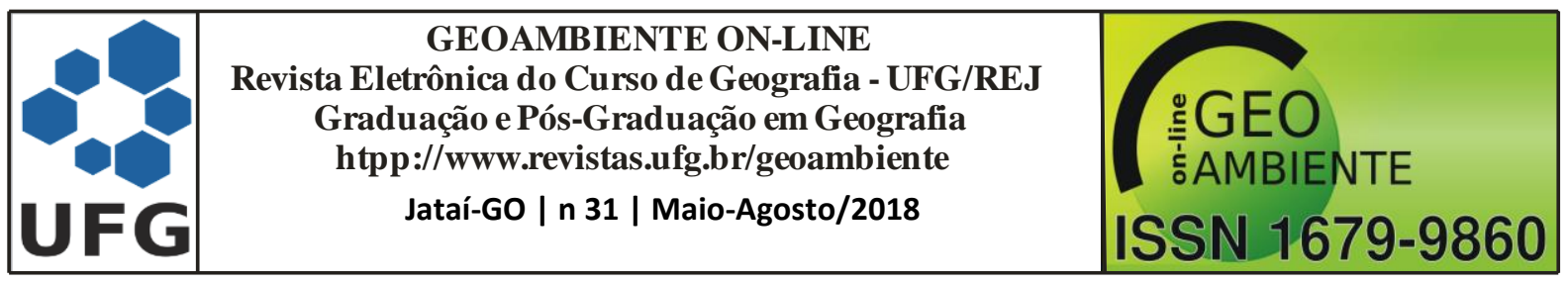

Norte da região Centro-Norte com a presença de bairros mais pobres, e, nas regiões Leste e porção Leste da Centro-Norte com habitações e prédios sofisticados, com a presença inclusive de sedes empresariais e de órgãos públicos, a exemplo da Câmara Municipal de Teresina (CMT), da Assembleia Legislativa do Piauí (ALEPI), da Águas e Esgotos do Piauí S.A (AGESPISA) e do campus da Universidade Federal do Piauí (UFPI).

\section{Múltiplos olhares sobre o mesmo objeto de estudo (rio Poti)}

Elencam-se neste repositório, estudos realizados entre os anos de 2008 e 2016. Os trabalhos foram realizados e publicados pelos seguintes mecanismos: Programa de PósGraduação em Desenvolvimento e Meio Ambiente (PRODEMA) e Programa de PósGraduação em Geografia (PPGGEO), ambos da Universidade Federal do Piauí (UFPI), Programa de Pós-Graduação em Geografia (PPGG) da Universidade Estadual Paulista “Júlio de Mesquita Filho" Campus Rio Claro (UNESP-RC) e Programa de Pós-Graduação em Geografia (PPGEO) da Universidade Federal de Pernambuco (UFPE).

Fora as contribuições realizadas através de estudos em cursos stricto sensu (mestrado e doutorado), buscou-se também análise de volumes dos seguintes periódicos: Revista Equador (UFPI), Revista GEAMA da Universidade Federal Rural de Pernambuco (UFRPE) e da Revista Okara, da Universidade Federal da Paraíba (UFPB). Soma-se as consultas em anais dos Simpósios de Geografia (SIMPGEO) da Universidade Estadual do Piauí (UESPI) durante os anos de 2013 e 2014, e do XII Simpósio Brasileiro de Climatologia Geográfica (SBCG) realizado em 2016 (Figura 2).

Destaca-se a quantidade de dissertações realizada sobre a temática, ressalta-se ainda que destas, quatro foram realizadas pelo PRODEMA/UFPI, curso caracterizado pelo desenvolvimento de pesquisas interdisciplinares sobre a relação meio ambiente e desenvolvimento. Sobre as teses (todas em Geografia), estas foram desenvolvidas por profissionais que atuam na cidade, mas que desenvolveram estudo sem universidades fora do Piauí, haja vista a ausência de curso de doutorado em Geografia no estado. No que se refere aos artigos (em eventos e em revistas), esses foram publicados tanto no estado quanto fora, em eventos local e nacional. 


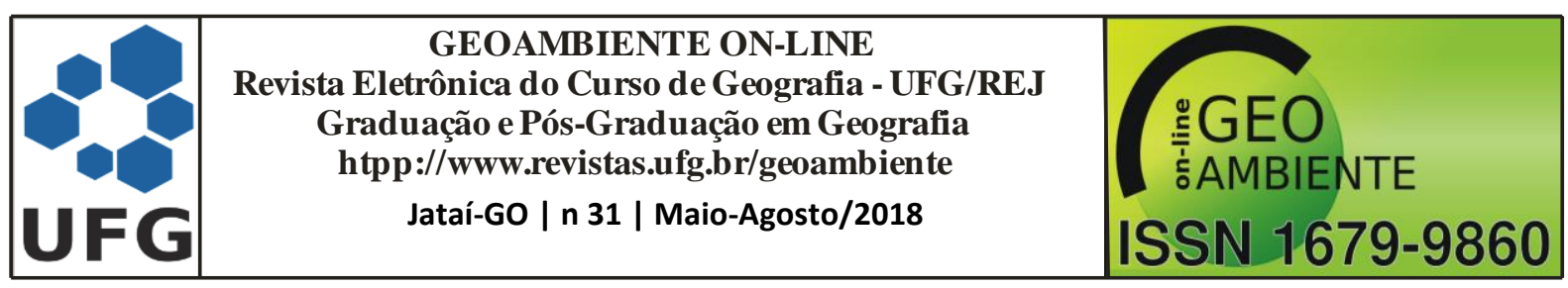

Figura 2 - Quantificação dos trabalhos sobre o rio Poti analisadas no estudo.

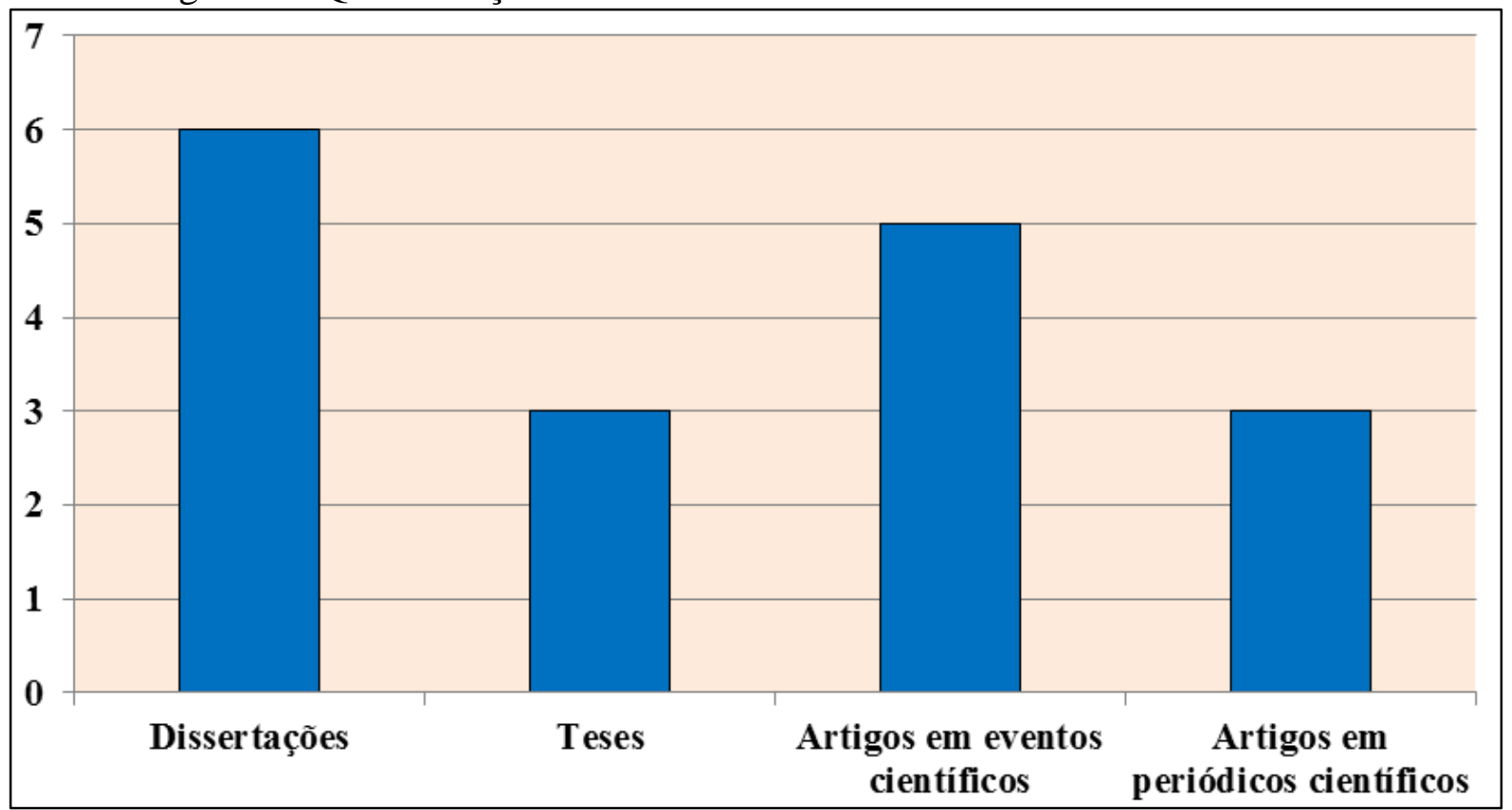

Organização: Os autores, 2017.

Os temas abordados foram diversos, assim como a escala de abrangência da área de estudo. Assim, optou-se em adaptar as escalas, em micro, estudos realizados em até quatro bairros, sendo estes próximos ou não; em meso configuram-se aqueles estudos desenvolvidos em regiões administrativas da cidade, por exemplo, a região Leste e; em macro, os estudos realizados ao longo do canal do rio, tanto no perímetro urbano quanto nos perímetros urbano e rural.

Quanto aos temas (figura 3) trabalhados, encontraram-se os seguintes: enchentes; inundações; riscos; perigos; vulnerabilidades (ambiental, social e socioambiental); atividades produtivas; uso, ocupação e cobertura da terra (e do solo); legislação (ambiental e urbana); qualidade ambiental e planejamento (ambiental e urbano). Sobre os conceitos de enchentes e inundações, apesar de para muitos serem considerados sinônimos, ambos possuem definições e características diferenciadas.

Enchente, por exemplo, é o aumento do nível da água, contudo, não há o transbordamento da calha fluvial, o que acontece quando do acontecimento de inundações, atingindo a planície de inundação.Quanto aos riscos, vulnerabilidades e perigo, mesmo sendo necessária uma discussão conjunta, estes três conjuntos foram separados na tabulação por serem definidos de forma diferenciada. 


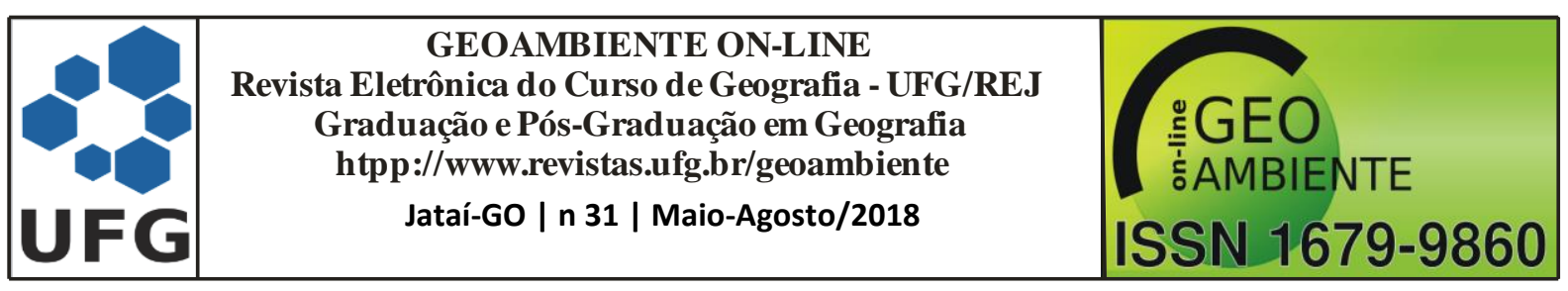

Figura3 - Quantificação dos temasdiscutidos pelos autores

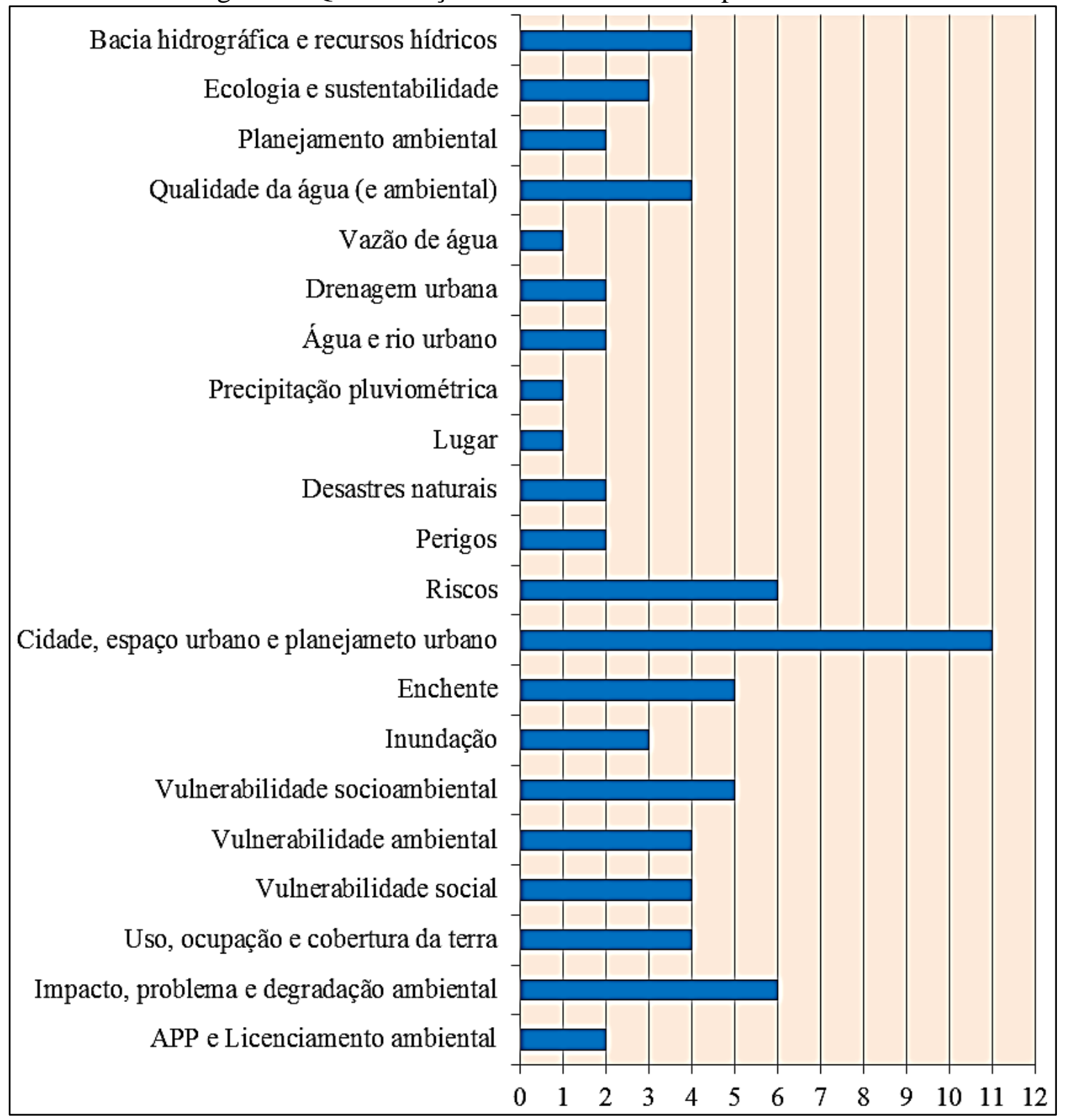

Organização: Os autores, 2017.

Os procedimentos metodológicos (quadro 2) que subsidiaram a discussão desses temas foram muitos, com destaque para pesquisa bibliográfica e técnica, utilização do geoprocessamento, verificação in loco, aplicação de questionários, realização de entrevistas, técnicas de geoprocessamento, de estatística e de laboratório, dentre outros procedimentos que, de acordo com os autores, supriram os objetivos e podem servir de referência para novos estudos. 


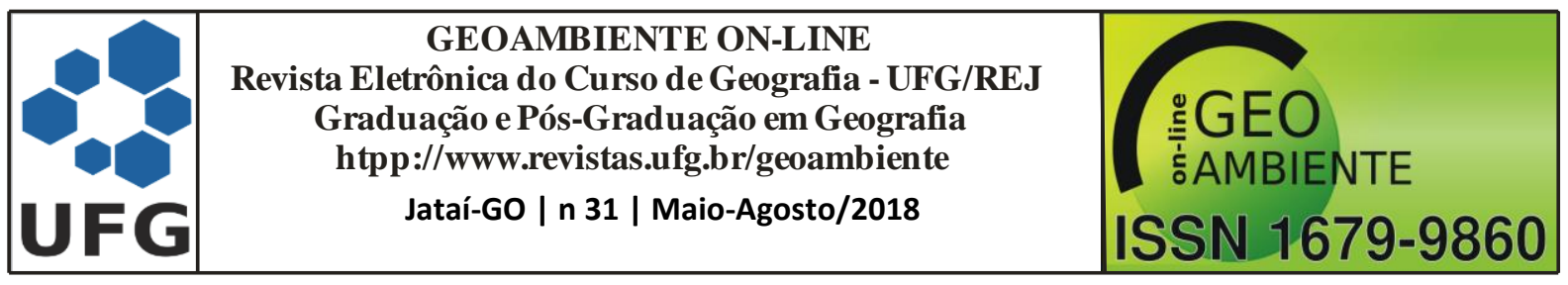

Quadro 2 - Síntese dos procedimentos metodológicos adotados pelos autores

\begin{tabular}{|c|c|}
\hline REFERÊNCIA & PROCEDIMIENTOS METODOLÓGICOS \\
\hline $\begin{array}{l}\text { Vieira (2008) } \\
\text { Chaves (2009) }\end{array}$ & $\begin{array}{l}\text { Pesquisa bibliográfica e técnica, utilização do } \\
\text { geoprocessamento, verificação in loco. }\end{array}$ \\
\hline Costa (2010) & $\begin{array}{l}\text { Pesquisa bibliográfica, documental e cartográfica, utilização } \\
\text { do geoprocessamento, verificação in loco e aplicação de } \\
\text { questionários. }\end{array}$ \\
\hline Lima Júnior (2011) & $\begin{array}{l}\begin{array}{l}\text { Pesquisa bibliográfica e técnica, utilização } \\
\text { geoprocessamento, verificação in loco. }\end{array} \\
\text { do }\end{array}$ \\
\hline Oliveira (2012) & $\begin{array}{l}\text { Pesquisa bibliográfica e documental, verificação in loco, } \\
\text { técnicas de laboratório e de geoprocessamento. }\end{array}$ \\
\hline$l(2013)$ & Pesquisa bibliográfica e verificação in loco \\
\hline $\begin{array}{l}\text { Araújo Neto, Silva e } \\
\text { Viana (2013) } \\
\end{array}$ & Pesquisa bibliográfica \\
\hline 2013) & ca e verificação in loco \\
\hline Feitos & $\begin{array}{l}\text { Pesquisa bibliográfica, documental e cartográfica, utilização } \\
\text { do geoprocessamento, verificação in loco e técnicas } \\
\text { estatísticas. }\end{array}$ \\
\hline $\begin{array}{l}\text { Nunes, Monteiro e } \\
\text { Paula (2014) }\end{array}$ & Pesquisa bibliográfica e verificação in loco \\
\hline Chaves (2015) & $\begin{array}{l}\text { Pesquisa bibliográfica, documental e cartográfica, utilização } \\
\text { do geoprocessamento, verificação in loco e aplicação de } \\
\text { questionários. }\end{array}$ \\
\hline Costa (2015) & $\begin{array}{l}\text { Pesquisa bibliográfica e técnica, utilização } \\
\text { geoprocessamento, verificação in loco. }\end{array}$ \\
\hline $\begin{array}{l}\text { Chaves e Tavares } \\
\text { (2015) }\end{array}$ & $\begin{array}{l}\begin{array}{l}\text { Pesquisa bibliográfica } \\
\text { geoprocessamento. }\end{array}\end{array}$ \\
\hline Silva e Aquino (2015) & $\begin{array}{l}\text { Pesquisa bibliográfica e documental, verificação in loco, } \\
\text { técnicas de laboratório e de geoprocessamento. }\end{array}$ \\
\hline Lima (2016) & \multirow{3}{*}{$\begin{array}{l}\text { Pesquisa bibliográfica e técnica, utilização do } \\
\text { geoprocessamento, verificação in loco. }\end{array}$} \\
\hline $\begin{array}{l}\text { Feitosa, Nunes e } \\
\text { Nóbrega (2016) }\end{array}$ & \\
\hline $\begin{array}{l}\text { Feitosa } \\
\text { Coelho }\end{array}$ & \\
\hline
\end{tabular}

Organização: Os autores, 2017.

Verifica-se, como dito anteriormente, a multiplicidade de metodologias aplicadas. Nessa etapa serão discutidos alguns trabalhos de forma agrupada por meio da temática geral (planejamento urbano e ambiental, enchentes e vulnerabilidades,problemática ambiental urbana, inundação e vulnerabilidades,e qualidade da água).

Nos estudos de Vieira (2008), Lima Júnior (2011) e Lima (2013; 2016), por exemplo, além da verificação in loco e dos levantamentos bibliográficos e teóricos, ocupou-se também na análise da legislação vigente, tanto a que dispõe sobre a conformidade legal das áreas de 


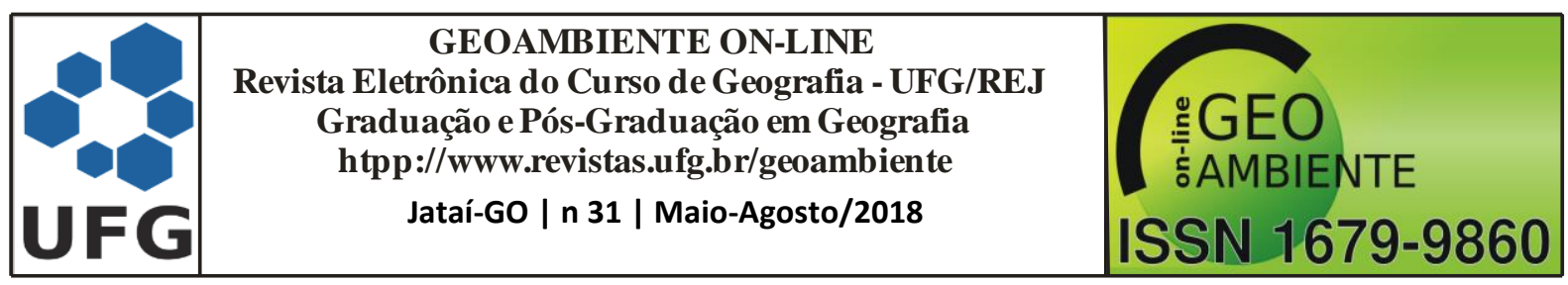

preservação, quanto a que se refere sobre a legislação municipal e de drenagem urbana. É necessário citar que os dois primeiros trabalhos discutiram o conceito de Área de Preservação Permanente (APP) antes do conhecido "Novo" Código Florestal (Lei 12.651/2012), considera-se ainda o fato da análise da legislação urbana em que discute e normatiza a drenagem urbana (em macro e microbacias de drenagem), em Zonas de Preservação Permanente, além da relação drenagem urbana, ocupação do solo e precipitação pluviométrica.

As temáticas abordadas pelos autores versam sobre a questão da cidade com a legislação e a forma de apropriação de espaços irregulares. Assim, os mesmos retrataram a pouca atuação do poder público na institucionalização e preservação necessária de áreas marginais ao Poti que desconsiderou a dinâmica conflituosa existente em relação aos assentamos humanos.

Já nos estudos realizados por Feitosa (2014), Feitosa, Nunes e Nóbrega (2016) e Feitosa, Nóbrega e Coelho Júnior (2016), os dados base foram disponibilizados em relatórios técnicos, além de elaboração de perfis topográficos, levantamento de dados de chuvas e tratamento estatístico. Destacam-se, nestes, as informações através do cálculo do Índice de Anomalia de Chuva (IAC), do cálculo do balanço hídrico climatológico, da aplicação da técnica dos quantis e análise episódica através de notícias de jornal para traçar informações sobre os riscos ambientais e vulnerabilidades associadas.

Nestes estudos, foram espacializados junto aos bairros que margeiam o Poti, quatro classes de vulnerabilidade social (altíssima, alta, média e baixa), de riscos (muito alto risco, alto risco, médio risco e baixo risco) que recaiu no mapa de vulnerabilidade socioambiental (altíssima, muito alta e média), tendo sempre o bairro Poti Velho como a área de risco eminente e de vulnerabilidade extremamente preocupante. O primeiro trabalho se destaca dos outros dois por ter a análise episódica das últimas enchentes (1985, 1995 e 2009) com o uso de matérias de jornal, além da construção de quatro cenários socioambientais.

Em Chaves $(2009 ; 2015)$ e Costa $(2010 ; 2015)$, a problemática socioambiental urbana é evidenciada através dos riscos em que a população teresinense está exposta, principalmente aquela localizada às margens do rio Poti. Técnicas de geoprocessamento e aplicação de questionários aos moradores das áreas caracterizam estes estudos e evidenciam o maior grau de exposição dos moradores localizados próximo à confluência do Poti com o rio Parnaíba, 


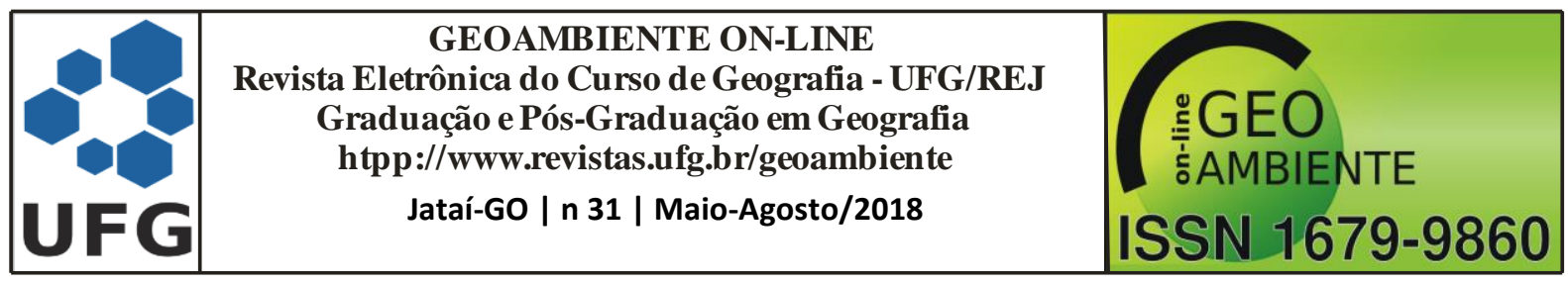

haja vista este segundo represar as águas do rio Poti, ocasionando o aumento da lâmina d'água havendo inundações mais significativas na área.

Os estudos resultaram em cenários conflituosos em relação aos aspectos ambientais e socioeconômicos. Os estudos comprovam que a cada ano os riscos socioambientais e a consequente vulnerabilidade socioambiental se acentuam, além das características de degradação ambiental intensa o que cria um preocupante processo de deterioração socioambiental.

Os autores relatam ainda a necessidade de intervenções que visam o reordenamento urbanístico da cidade e que ofereça à sociedade teresinense uma satisfatória qualidade de vida. Costa (2010) cita os exemplos bem sucedidos nas cidades do Rio de Janeiro (Rio de Janeiro), Belo Horizonte (Minas Gerais) e São Luís (Maranhão).

Oliveira (2012) e Silva e Aquino (2015) discutem através do Índice de Qualidade da Água (IQA) a qualidade da água (temporal e espaço-temporal) do rio Poti, as fontes de poluição e contaminação, e a implicância destas sobre a população local. Técnicas de laboratório e de campo tornaram-se necessárias, sendo que, as de campo exigem certo cuidado na coleta da amostra de água para não causar distúrbios nos parâmetros físicos, químicos e biológicos analisados em laboratório. Pontos de coleta, horários e luminosidade, por exemplo, são fatores que podem modificar os parâmetros e deturpar a realidade da área e comprometer o estudo.

As duas literaturas indicaram que, por meio do monitoramento da qualidade da água, o rio Poti sofre com um significativo grau de poluição e contaminação principalmente onde há um maior adensamento populacional (zona urbana) através do lançamento de efluentes domésticos e do ineficiente sistema de esgotamento sanitário da cidade.

Os autores constaram ainda a necessidade de ampliação do sistema de esgotamento sanitário e de tratamento de esgoto na cidade, além da eliminação de ligações irregulares que degradam tanto o meio ambiente quanto a saúde da população. Afirmam ainda que o aumento da carga poluente prejudicam a atividade pesqueira e a diminuição da quantidade de espécies da fauna e da flora da área. Recomendam ainda o manejo sustentável do solo e da água, monitoramento e fiscalização ambiental. 




Nos estudos de Nunes et al (2013), Araújo Neto, Silva e Viana (2013), Nunes, Monteiro e Paula (2014) e Chaves e Tavares (2015), a perspectiva na relação espaço urbano e rio Poti se difere das demais abordagens.

Nunes, Monteiro e Paula (2014) e Nunes et al(2013) discutem o Poti frente às pressões antrópicas causadas pela urbanização e atividades produtivas. As pressões destacadas pelos autores são: atividade de mineração (região Sul da cidade); substituição da cobertura vegetal (regiões Leste e Centro-Norte) para empreendimentos públicos e privados; e lançamento de esgoto, tornando-se mais evidentes e preocupantes quando da "entrada" do rio nas áreas mais densamente ocupadas.

Sobre a atividade de mineração, os estudos demonstraram a importância dessa atividade para o desenvolvimento econômico de Teresina. Contudo, a geração de danos ambientais decorrentes da extração são nítidos, destacam-se: compactação do solo; retirada da vegetação; poluição do ar; água e do solo; descaracterização do canal fluvial e redução da biodiversidade. Torna-se evidente a dualidade entre a natureza e a sociedade se apresentando de maneira conflituosa na extração de areia e na preservação ambiental.

Em outros estudos, também pôde-se perceber o nível de ocupação nas áreas ribeirinhas do rio Poti “pois são áreas que estão localizados inúmeros prédios residenciais e comerciais, sendo que estes estão ligados diretamente à problemática da poluição do rio, porque são essas construções as maiores lançadoras de efluentes e resíduos sólidos no Poti” (ARAÚJO NETO, SILVA e VIANA, 2013, p. 86).

Os autores consideram que o uso racional e consciente dos recursos naturais poderá favorecer um desenvolvimento sustentável, evitando assim cenários de degradação sobre os sistemas ambientais. Afirmam ainda que a diminuição das áreas verdes e o aumento da pavimentação são casos que favorecem o desequilíbrio do meio natural.

Chaves e Tavares (2015) representam a problemática socioambiental urbana através de análise das precipitações sobre a cidade que influi sobremaneira na ocorrência de inundações, o que deixa a população já vulnerável socialmente, expostas à vulnerabilidade socioambiental.

Os autores relatam ainda que todas as regiões administrativas da cidade (Centro-Norte, Sul, Sudeste e Leste) possuem setores com risco de inundação e que, de acordo com o mapeamento do Serviço Geológico do Brasil (CPRM), a área mais crítica é aquela representada pela Centro-Norte, derivado, em grande parte, pela influência do rio Parnaíba. 


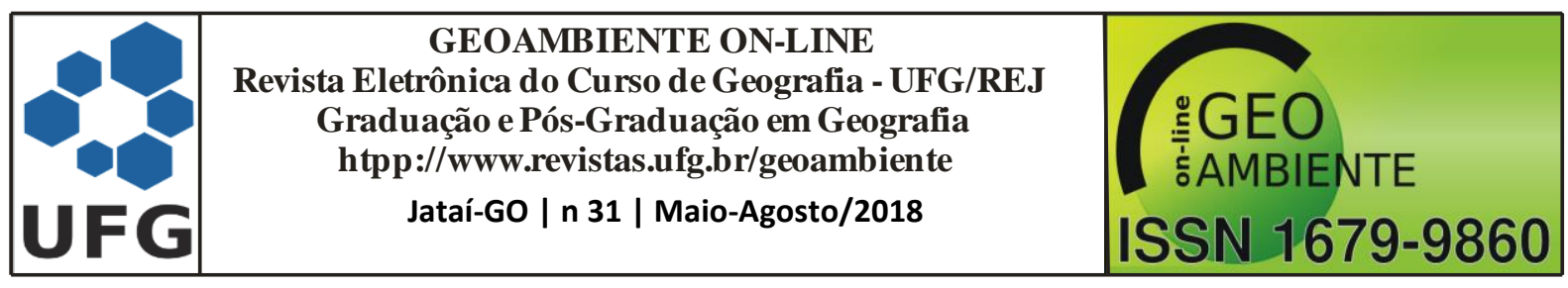

Constata-se ainda que aproximadamente $70 \%$ das pessoas que moram em setores de riscos às inundações em Teresina residem na região Centro-Norte da cidade, além de $9 \%$ se encontrarem na região Sul, $9 \%$ na região Sudeste e $12 \%$ na região Leste.

O crescimento urbano desordenado na cidade de Teresina nas últimas décadas tem gerado inúmeros e distintos problemas ambientais sobre o rio Poti, como o lançamento de esgoto a céu aberto, de afluentes e resíduos sólidos de forma ilegal, ocupação irregular das áreas ribeirinhas dentre outras ações que exigem uma gestão mais eficaz e rigorosa dos recursos e ambientes naturais.

Nesse bojo representativo, as relações da sociedade sobre a natureza se ligam à medida que a primeira avança no seu processo de desenvolvimento socioeconômico.Diante disso, transfigurando e modificando a natureza até então intacta, tornando-a uma natureza social, através das técnicas de produção (re)criadas pelo homem. No que se refere à espacialização (Figura 4) destes estudos, todas as regiões administrativas (Sul, Leste, Sudeste e CentroNorte) de Teresina foram averiguadas.

Percebe-se, de acordo com a figura 4, a quantidade significativa de trabalhos realizados em macroescala o que contemplou todas as regiões administrativas de Teresina, infere-se assim que a análise comparativa desses estudos propicia uma análise espaçotemporal crítica comparativa entre os mesmos.

Embora discutidos tanto com metodologias quanto em áreas distintas, tais estudos configuram como importante fonte sobre as vulnerabilidades e qualidade ambiental do município de Teresina. Outras compilações se fazem necessárias para compreender a situação ambiental e outros aspectos que se fizerem pertinentes, além de facilitar um olhar panorâmico sobre os estudos locais destas temáticas.

A análise destes trabalhos configura ainda em um retrato da situação ambiental (e socioambiental) de Teresina objetivando visualizar as características de cada área, podendo auxiliar ainda no planejamento e na implantação de políticas públicas. 


\begin{tabular}{|c|c|c|}
\hline & $\begin{array}{c}\text { GEOAMBIENTE ON-LINE } \\
\text { Revista Eletrônica do Curso de Geografia - UFG/REJ } \\
\text { Graduação e Pós-Graduação em Geografia } \\
\text { htpp://www.revistas.ufg.br/geoambiente } \\
\text { Jataí-Go | n } 31 \text { | Maio-Agosto/2018 }\end{array}$ & $\begin{array}{c}\text { :GEO } \\
\text { ISAMBIENTE } \\
\text { ISSN 1679-9860 }\end{array}$ \\
\hline
\end{tabular}

Figura 4 - Espacialização dos estudos analisados em escalas de abordagem



Elaboração: Os autores, 2017. 


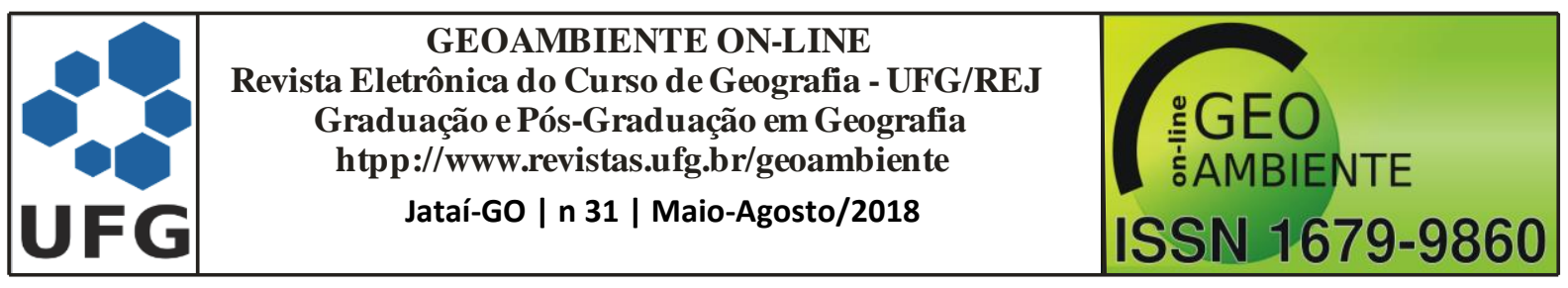

\section{Considerações Finais}

Com a realização deste estudo, confirma-se a constante dinâmica existente nas cidades, principalmente pelos agentes responsáveis pela modelagem do espaço urbano apontados por Corrêa (2005), como os proprietários fundiários, os donos dos meios de produção, os promotores imobiliários, os grupos sociais excluídos e o Estado.Neste contexto, a dualidade envolvendo o espaço urbano e sua problemática ambiental, garante uma complexidade nesse nexo, cabendo à Geografia sua análise e discussão, ciência detentora de contribuições teórico-metodológicas e práticas que ajudam a suprir as discussões sobre a temática.

Dos 17 trabalhos analisados (6 dissertações, 3 teses, 5 artigos em eventos científicos e 3 em artigos em periódicos científicos) os conceitos discutidos foram diversos, assim como as metodologias abordadas, conferindo assim múltiplos olhares sobre o rio Poti.Em suma, ficou evidenciado a íntima relação entre o rio Poti e a problemática socioambiental de Teresina, haja vista a pressão antrópica presente.

Ao fim, apesar dos avanços científicos em torno da questão ambiental apontadas e discutidas neste artigo é fundamental mais discussões sobre o assunto, sob o olhar geográfico bem como um olhar de outras ciências e profissionais que se preocupam com o rio Poti e seus assuntos socioambientais.

Sugere-se portanto, a realização de outros estudos sobre estado da arte, abarcando não só dissertações, teses e artigos, mas também monografias de graduação/especialização e eventos/reuniões que debatam essa temática. Por essa razão, aqui não está apresentada uma conclusão final, pelo contrário, haja vista o potencial de novas pesquisas sobre o rio, havendo assim a necessidade de novas investigações e consolidação da preocupação sobre o ambiente.

\section{Agradecimentos}

À Coordenação de Aperfeiçoamento de Pessoal de Nível Superior (CAPES) pela concessão de bolsa de mestrado ao primeiro autor. Aos profissionais que se dedicam a produção de conhecimentos sobre o rio Poti e a cidade de Teresina/PI.

\section{Referências}




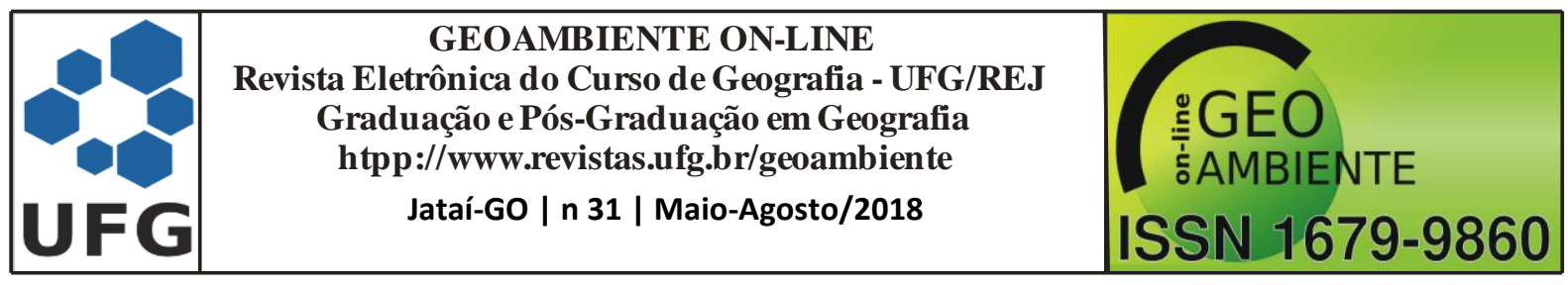

ARAÚJO NETO, Adalgiso Barbosa; SILVA, Gracielly Portela; VIANA, Bartira Araújo da Silva. Ação antrópica na bacia do rio Poti no perímetro urbano de Teresina. In: SIMPÓSIO DE GEOGRAFIA DA UESPI, 13., 2013, Teresina. Anais...Teresina, 2013.

CALLAI, Helena Copetti. Estudar o lugar para compreender o mundo. In: CASTROGIOVANNI, Antonio Carlos; CALlAI, Helena Copetti; KAERCHER, Nestor André. Ensino de geografia práticas e textualizações no cotidiano. Porto Alegre: Mediação, 2000.

CARLOS, Ana Fani Alessandri. A cidade. São Paulo: Contexto, 2007.

CHAVES, Sammya Vanessa Vieira.A vulnerabilidade socioambiental em Teresina, Piauí.Teresina, 2008, 180f. Dissertação (Mestrado em Desenvolvimento e Meio Ambiente) Universidade Federal do Piauí.

.Vulnerabilidade às inundações em Teresina, Piauí. Rio Claro, 2015. 231f.Tese (Doutorado em Geografia) - Universidade Estadual Paulista "Júlio de Mesquita Filho".

; TAVARES, A. C. As intensas precipitações em Teresina, Piauí e as inundações. Equador, v. 4, n. 3, 2015.

CORRÊA, Roberto Lobato. O espaço urbano. São Paulo: Ática, 2005.

COSTA, Renato Sérgio Soares. Processo contraditório de uso e ocupação em Áreas de Preservação Permanente, às margens do rio Poti - Teresina, Piauí.Rio Claro, 2015. 192f.Tese (Doutorado em Geografia) - Universidade Estadual Paulista "Júlio de Mesquita Filho".

.Riscos socioambientais e ocupação irregular em áreas de enchentes nos bairros:Olarias, Poti Velho, Alto Alegre, São Francisco e Mocambinho - Teresina (PI). Rio Claro, 2010, 175f. Dissertação (Mestrado em Geografia) - Universidade Estadual Paulista "Júlio de Mesquita Filho".

DESCHAMPS, Marley Vanice. Vulnerabilidade socioambiental da Região Metropolitana de Curitiba. Curitiba, 2004. 192f. Tese (Doutorado em Desenvolvimento e Meio Ambiente) Universidade Federal do Paraná.

FEITOSA, Maria Suzete Sousa. Enchentes do rio Poti e vulnerabilidades socioambientais na cidade de Teresina-PI.Recife, 2014. 218f. Tese (Doutorado em Geografia) - Universidade Federal de Pernambuco. 


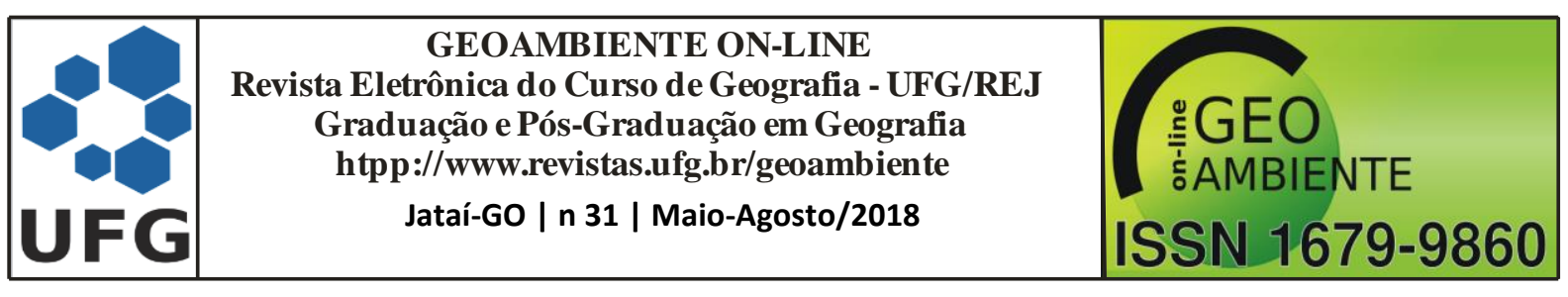

; NÓBREGA, Ranyére da Silva; COELHO JUNIOR, José

Machado.Vulnerability environmental and flood risk in rio Poti, Teresina, Brazil. GEAMA, v.5, n.1, 2016.

;NUNES, Hikaro Kayo de Brito; NÓBREGA, Ranyére da Silva. Transformações do meio urbano, enchentes e risco no baixo curso do rio Poti em Teresina PI. In: SIMPÓSIO BRASILEIRO DE CLIMATOLOGIA GEOGRÁFICA, 12., 2016, Goiânia. Anais...Goiânia, 2016.

FERNANDES, Edésio. Estatuto da cidade: o grande desafio para os juristas brasileiros. In CONGRESSO BRASILEIRO DE DIREITO URBANÍSTICO, 2., 2002, Porto Alegre. Anais... Porto Alegre: Editora, 2002.

JORGE, Maria do Carmo Oliveira. Geomorfologia urbana: conceitos, metodologias e teorias. In: GUERRA, Antonio José Teixeira. Geomorfologia urbana. Rio de Janeiro: Bertrand Brasil, 2011. cap. 4, p. 117-145.

LIMA JÚNIOR, João Macedo. Cidade, solo urbano e drenagem:abordagem sobre as inundações em área da zona Leste da cidade de Teresina, Piauí.Teresina, 2011, $120 f$. Dissertação (Mestrado em Desenvolvimento e Meio Ambiente) - Universidade Federal do Piauí.

LIMA, Aline de Araújo. Análise do uso e ocupação (do solo) no entorno da planície de inundação no bairro São João município de Teresina - Piauí. In: SIMPÓSIO DE GEOGRAFIA DA UESPI, 13., 2013, Teresina. Anais...Teresina, 2013.

.Análise geossistêmica e gestão ambiental na cidade de Teresina - Piauí.

Teresina, 2016. 137f.Dissertação (Mestrado em Geografia) - Universidade Federal do Piauí.

NUNES, Hikaro Kayo de Brito. Vulnerabilidade socioambiental dos setores censitários às margens do rio Poti no município de Teresina - Piauí.Teresina, 2017. 171f. Dissertação (Mestrado em Geografia) - Universidade Federal do Piauí.

; MONTEIRO, Gessica Maria Mesquita; PAULA, Maria Luzineide Gomes. Intervenções humanas no entorno dos corpos hídricos: análise do baixo curso do rio Poti na cidade de Teresina/Piauí. In: SIMPÓSIO DE GEOGRAFIA DA UESPI, 14., 2014, Teresina. Anais...Teresina, 2014. 


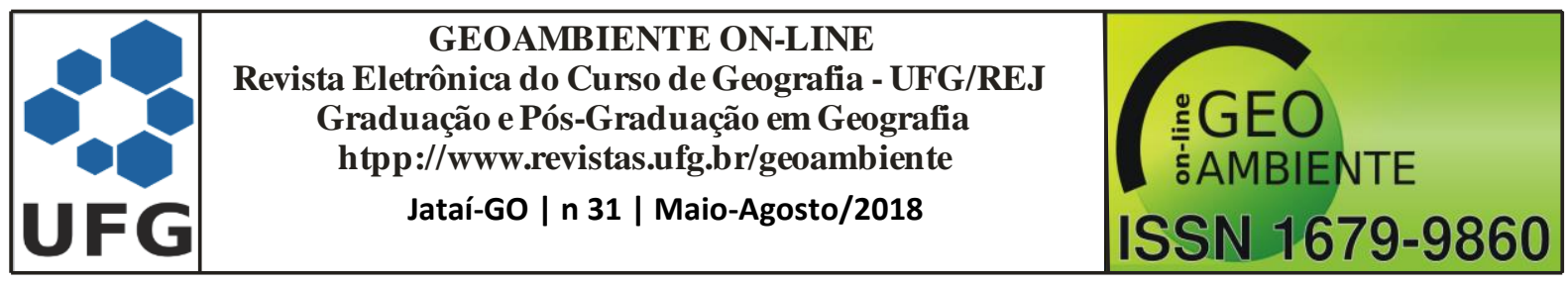

.(et al).Atividade produtiva de extração mineral de areia no leito do rio Poti, em Teresina - PI. In: SIMPÓSIO DE GEOGRAFIA DA UESPI, 13., 2013, Teresina. Anais...Teresina, 2013.

OLIVEIRA, LivâniaNorberta. Estudo da variabilidade sazonal da qualidade da água do rio Poti em Teresina e suas implicações na população local. Teresina, 2012. 113f. Dissertação (Mestrado em Desenvolvimento e Meio Ambiente) - Universidade Federal do Piauí.

PEIXOTO, Monica Campolina Diniz. Expansão urbana e proteção ambiental: um estudo a partir do caso de Nova Lima/MG. ANPUR, 2005, Salvador.

PELLING, Mark. The vulnerability of cities: natural disasters and social resilience.London: Earthscan, 2003.

REIS, Carla Munhoz Melchior. Impactos ambientais gerados na implantação de habitações populares na cidade de São Paulo. São Paulo, 2005. 78f. Trabalho de Conclusão de Curso (Monografia de Engenharia de Produção) - Universidade Anhembi Morumbi.

RODRIGUES, Arlete Moysés. Produção e consumo do e no espaço: problemática ambiental urbana. São Paulo: Ed. Hucitec, 1998.

ROSSATO, Ricardo. Século XX:urbanização e cidadania. Santa Maria: Palotti, 1996.

SANTOS FILHO, Raphael David. Antropogeomorfologia urbana. In: GUERRA, Antonio José Teixeira. Geomorfologia urbana. Rio de Janeiro: Bertrand Brasil, 2011. cap. 7, p. 227246.

SEMPLAN. Secretaria Municipal de Planejamento e Coordenação - Prefeitura de Teresina.Teresina:caracterização do município, 2016.

SILVA, Flávio Rodrigues; AQUINO, Cláudia Maria Sabóia. Análise da qualidade da água do rio Poti, entre a ponte da Primavera e a ponte Leonel Brizola, Teresina, Piauí. OKARA: Geografia em debate, v.9, n.1, 2015.

SOUZA, Marcelo Lopes. ABC do desenvolvimento urbano. Rio de Janeiro: Bertrand Brasil, 2008.

SPÓSITO, Maria Encarnação Beltrão. Capitalismo e urbanização. São Paulo: Contexto, 1988.

VASCONCELOS, Pedro de Almeida. As metamorfoses do conceito de cidade. Mercator, v. 14, n. 4. 2015. 


\begin{tabular}{|c|c|c|}
\hline & $\begin{array}{c}\text { GEOAMBIENTE ON-LINE } \\
\text { Revista Eletrônica do Curso de Geografia - UFG/REJ } \\
\text { Graduação e Pós-Graduação em Geografia } \\
\text { htpp://www.revistas.ufg.br/geoambiente } \\
\text { Jataí-Go | n } 31 \text { | Maio-Agosto/2018 }\end{array}$ & $\begin{array}{c}\text { ISEN 1679-9860 } \\
\text { G }\end{array}$ \\
\hline
\end{tabular}

VERONA, Juliana Augusta; GALINA, Márcia Helena; TROPPMAIR, Helmut. Geografia e questões ambientais. Mercator, v. 2, n. 4, p. 87-97. 2003.

VIEIRA, Daniele Melo.Análise dos impactos ambientais resultantes do uso e ocupação do solo e avaliação da conformidade legal e da gestão nas Áreas de Preservação Permanente do rio Poti, em Teresina, PI/Brasil. Teresina, 2008. 195f. Dissertação (Mestrado em Desenvolvimento e Meio Ambiente) - Universidade Federal do Piauí. 